\title{
SOBRE EL ESTADO DE SITIO, SU RÉGIMEN JURÍDICO Y EL CONTROL JURISDICCIONAL DE SU DECLARACIÓN
}

POR

\author{
CARLOS GARRIDO LÓPEZ \\ Profesor Titular de Derecho Constitucional \\ Universidad de Zaragoza
}

\section{NATURALEZA JURÍDICA DEL ESTADO DE SITIO Y PRESUPUESTOS DE SU DECLARACIÓN}

El estado de sitio previsto en nuestro ordenamiento jurídico representa la última ratio del Estado de Derecho en su crisis. Su declaración sustituye temporalmente el estatuto ordinario del poder y de ciertas garantías, pero no arrumba la normatividad constitucional. El estado de sitio es, pese a la gravedad que entraña su utilización, una garantía de la Constitución, no su desahucio. Es un recurso extraordinario que habilita a la par que limita la máxima concentración de poder; es, en fin, frente a otras fórmulas excepcionales, una comisión condicionada para la acción con la que encarar la anormalidad sin renunciar a la fuerza normalizadora del Derecho'.

\footnotetext{
1 Aunque hubo propuestas en ese sentido, la Constitución de 1978 no contiene ninguna "cláusula general», o comisión incondicionada para la acción, similar al apoderamiento en favor del Presidente de la República permitido por el artículo 16 de la Constitución francesa de 1958. Durante el proceso constituyente, el diputado
} 
Heredero del estado de sitio ficticio de origen francés ${ }^{2}$, su rasgo distintivo sigue siendo, pese a los cambios operados en su regulación, la sustitución de la autoridad civil por la militar en la gestión de la emergencia, así como la eventual extensión del ámbito de la jurisdicción castrense. Su constitucionalización, por primera vez en nuestra historia política ${ }^{3}$, resultó inconcusa, aunque inicialmente existiera cierta indecisión acerca de la denominación más adecuada para referirse a él. A tal efecto, la Ponencia constitucional manejó indistintamente las expresiones "estado de guerra" y "estado de sitio". El artículo 94.4 del Anteproyecto de Constitución, publicado en enero de 1978, se decantó por la primera, tradicional en nuestra legislación de orden público ${ }^{4}$, pero tras el informe de la Ponencia, publicado el 17 de abril de 1978, dicha expresión fue sustituida, sin mediar enmienda alguna, por la de "estado de sitio", que

López Rodó (Alianza Popular) presentó una enmienda de adición de un nuevo artículo, el 54 bis, en la que, a semejanza del modelo francés, proponía que el Rey, como Jefe del Estado, pudiera adoptar ante crisis de extrema gravedad las medidas exigidas por las circunstancias a propuesta conjunta del Presidente del Gobierno y los Presidentes de las Cámaras legislativas. Dicha enmienda fue defendida en la Comisión de Asuntos Constitucionales por su autor y por el diputado de su mismo grupo, Fraga Iribarne, pero fue rechazada por su incompatibilidad con la noción de monarquía parlamentaria y racionalizada que el constituyente pretendía instaurar, por la indeterminación de las "medidas necesarias" que posibilitaría adoptar y por estimarse suficiente para afrontar a la excepción los estados críticos previstos en el artículo 108 del proyecto. Diario de Sesiones del Congreso de los Diputados, Comisión de Asuntos Constitucionales y Libertades Públicas, núm. 76, 30 de mayo de 1978, pp. 2768-2775.

2 Sobre la gestación del état de siège, P. Cruz ViLlalón, El estado de sitio y la Constitución, Centro de Estudios Constitucionales, Madrid, 1980, pp. 302-318 y 367393.

${ }^{3}$ Los estados de sitio ficticios fueron, como es sabido, una constante en la agitada historia constitucional de España, pero a excepción de la fugaz mención del estado de guerra en la Constitución de 1931, nuestros textos fundamentales se limitaron a regular la suspensión de derechos como eventual contenido de las situaciones críticas, difiriendo al legislador de orden público la importante tarea de concretar los tipos de estados excepcionales y su diferente naturaleza. F. FERNÁNDEZ SEgAdo, El estado de excepción en el Derecho constitucional español, Edersa, Madrid, 1977, pp. 80-142.

${ }^{4}$ Desde su aparición en España en 1834-1835 hasta la primera Ley de Orden Público, los moderados emplearon la expresión "estado de sitio" mientras los progresistas preferían declarar el "estado de guerra», denominación que prosperó legislativamente a partir de la Ley de González Brabo de 1867. Véanse, P. CRUz VILLALón, El estado de sitio y la Constitución, cit., pp. 319-365, y M. BALlBÉ, Orden público y militarismo en la España constitucional (1812-1983), Alianza, Madrid, 1983, pp. 116-127, 154-179 y 189-192. 
se mantuvo hasta el final del proceso constituyente ${ }^{5}$. El abuso de los estados de guerra en el pasado y el deseo de evitar la menor confusión con las situaciones de guerra formalmente declarada o con las materialmente bélicas en que España pudiera verse implicada debieron influir en ello.

El constituyente reguló el procedimiento para la declaración del estado de sitio, estableció sus límites temporales y garantías (arts. 116 y 169 de la CE) y concretó sus principales efectos (arts. 55.1 y 117.5 de la CE). No quiso, empero, agotar el derecho de excepción, ni convertir el estado de sitio político en un instituto inmediatamente aplicable por los poderes públicos a partir de su enunciado constitucional, por lo que remitió al legislador la concreción de los supuestos críticos habilitantes de su declaración ${ }^{6}$. "Una ley orgánica regulará los estados de alarma, excepción y sitio, y las competencias y limitaciones correspondientes", proclama el artículo 116.1 de la $\mathrm{CE}$, convirtiendo esa regulación legal en pieza fundamental del sistema de fuentes del derecho español de excepción. La naturaleza constitucional del estado de sitio quedó así indeterminada, diferida a la decisión del legislador, que tanto podía hacer de él un instituto cualitativamente distinto a los estados excepcionales de naturaleza civil como, al estilo del estado de guerra de las Leyes de Orden Público de 1933 y 1959, considerarlo un híbrido, a un tiempo tercer grado de las emergencias de orden público e instrumento específico para hacer frente a insurrecciones armadas ${ }^{7}$.

Aunque no faltaban argumentos a favor de la tesis "gradualista" de dicho estado8, la Ley Orgánica 4/1981, de 1 de junio, de los estados de

\footnotetext{
5 Véanse, respectivamente, los Boletines Oficiales de las Cortes, núm. 44, de 5 de enero de 1978, pp. 684-685, y núm. 82, de 17 de abril de 1978, p. 1575.

6 En nombre del Grupo Parlamentario Comunista, el diputado Sánchez Montero propuso circunscribir las causas de este estado crítico a las agresiones exteriores a la soberanía e independencia de España, pero su enmienda no prosperó. Constitución española. Trabajos parlamentarios, vol. I, Cortes Generales, Madrid, 1980, pp. 414-415.

7 En este sentido, los artículos 48 y 35.a) de las Leyes de Orden Público de 1933 y 1959, respectivamente. En la doctrina, véase F. FERNÁNDEZ SEGADO, El estado de excepción en el Derecho constitucional español, cit., pp. 130-137 y 252-259, y, del mismo autor, "La función de las Fuerzas Armadas en el estado de sitio, en el marco de la Constitución de 1978", en L. Prieto y C. BroouetAs (eds.), Libertades publicas y Fuerzas Armadas, Ministerio de Educación y Ciencia, Madrid, 1986, pp. 217-230.

8 Nuestro derecho histórico se adscribió a esta concepción gradualista sin excepción. Las garantías que en la Constitución de 1978 rodean la declaración de cada uno de los estados críticos reflejan, por su parte, un progresivo protagonismo del Congreso. Y escalonado está, asimismo, el eventual efecto suspensivo de los di-
} 
alarma, excepción y sitio (LOAES), optó finalmente por subrayar la naturaleza violenta de la emergencia y la especificidad de los bienes amenazados. De acuerdo con su artículo 32.1, procede la declaración del estado de sitio "cuando se produzca o amenace producirse una insurrección o acto de fuerza contra la soberanía o independencia de España, su integridad territorial o el ordenamiento constitucional». Si, como ha subrayado la doctrina, la declaración del estado de excepción supone la existencia de una crisis de orden público, "la declaración del estado de sitio supone una crisis profunda del propio Estado $"{ }^{9}$, puesto que las emergencias que justifican su declaración afectan o amenazan elementos básicos del Estado, como el territorio, el derecho y el poder. El estado de sitio sería de este modo la respuesta institucional singularizada frente a todos aquellos hechos que pusieran en peligro la supervivencia del Estado como comunidad política organizada.

Al exigir, no obstante, que la insurrección o acto de fuerza que se produzca o amenace producirse «no pueda resolverse por otros medios", el artículo 32.1 de la LOAES también posibilita un uso gradualista del estado de sitio. Ello, en palabras de Cruz Villalón, "tiene su razón de ser en los supuestos de agresión interna, dado el potencial de las fuerzas y cuerpos de seguridad, que pueden no hacer necesario siquiera la declaración del estado de excepción o que, si pueden exigir la declaración de este estado, puede que no sea preciso pasar más allá del mismo ${ }^{10}$. Pero, precisamente por ser la medida extraordinaria más extrema frente a las crisis, no cabe descartar que un agravamiento de los supuestos que motivaron la declaración del estado de excepción de-

versos estados sobre las garantías constitucionales (arts. 55.1 y 117.5 de la CE). Partidario de la gradualidad se mostró, además, el Informe de la Ponencia constitucional, según el cual debían «recogerse [...] las tres situaciones excepcionales clásicas para graduar la mayor o menor intensidad de aquéllas" (Boletín Oficial de las Cortes, núm. 82, 17 de abril de 1978, p. 1574), aunque a tenor de las intervenciones realizadas con posterioridad por los portavoces centristas, el estado de alarma, al menos, parecía destinado a ser un instituto cualitativamente distinto a los estados de excepción y sitio con el que hacer frente a "eventos catastróficos, naturales o no". En este sentido se pronunciaron los diputados de Unión de Centro Democrático, Cisneros Laborda y Apostúa Palos, en la Comisión de Asuntos Constitucionales y en el Pleno del Congreso, respectivamente (Diario de Sesiones del Congreso de los Diputados, Comisión de Asuntos Constitucionales, núm. 84, 8 de junio de 1978, p. 3075, y Diario de Sesiones del Congreso de los Diputados, Pleno, núm. 109, 13 de julio de 1978, p. 4238).

9 E. Álvarez Conde, Curso de Derecho Constitucional, vol. I, Tecnos, Madrid, 1992, p. 438.

10 P. CRuz Villalón, "El nuevo derecho de excepción», Revista Española de Derecho Constitucional, núm. 2, 1981, p. 102. 
sencadene la declaración del estado de sitio si, llegado el caso, los fundamentos del Estado se ven afectados. De la enumeración expresa de esos fundamentos en el artículo 32.1 LOAES se desprende, sin embargo, que tal régimen excepcional posee entidad y naturaleza claramente diferenciadas de los restantes estados críticos ${ }^{11}$.

El uso de la violencia o su amenaza determina en el estado de sitio que el ejercicio del poder represivo del Estado se transfiera de la autoridad civil a la militar. $Y$ la identidad existente entre los supuestos de su declaración (art. 32.1 de la LOAES) y las misiones constitucionales de las Fuerzas Armadas (art. 8.1 de la CE) implica necesariamente la intervención del aparato militar estatal. A diferencia de nuestros tradicionales estados de guerra, concebidos en la legislación de orden público para hacer frente a emergencias de orden interno, el estado de sitio previsto en el artículo 116.4 de la CE pretende salvaguardar el Estado constitucional de los actos violentos procedentes tanto del interior como del exterior de nuestras fronteras. Los presupuestos de hecho de su declaración así lo evidencian. Por su objeto, los atentados o amenazas contra el ordenamiento constitucional, tales como golpes de Estado, insurrecciones o rebeliones tipificadas como delito en el artículo 79 del vigente Código Penal Militar, tienen un origen interno. La integridad territorial, sin embargo, puede verse afectada desde dentro, mediante iniciativas secesionistas violentas, por ejemplo, pero también mediante invasiones o incursiones armadas procedentes del exterior. Las agresiones contra la soberanía e independencia de España, en fin, no pueden tener sino un origen externo, y aunque frente a ellas los recursos bélicos sean la única defensa, el estado de sitio constituye un complemento institucional necesario ante sus eventuales efectos internos ${ }^{12}$.

\section{ESTADO DE SITIO, DECLARACIÓN DE GUERRA Y «TIEMPO» $O$ «TIEMPOS» DE GUERRA}

Pese a la intervención de las Fuerzas Armadas, el estado de sitio no pretende facilitar el desarrollo de una campaña militar, ni los medios es-

11 F. Fernández Segado, "La Ley Orgánica de los estados de alarma, excepción y sitio", Revista de Derecho Político, núm. 11, 1981, pp. 112, y "La función de las Fuerzas Armadas en el estado de sitio, en el marco de la Constitución de 1978", cit., pp. 236-237. En el mismo sentido, J. M. SerRANo AlBerCA, "Comentario al artículo 116", en F. Garrido Falla (dir.), Comentarios a la Constitución, 3. ${ }^{a}$ Ed., Civitas, Madrid, 2001, pp. 1803-1804.

12 P. CRuz Villalón, Estados excepcionales y suspensión de garantías, Tecnos, Madrid, 1984, pp. 108-112. 
pecíficos de la defensa nacional, sino "asegurar y mantener el orden constitucional ante agresiones armadas internas o ante los efectos internos de acciones externas de la misma índole ${ }^{13}$. Es, por tanto, un estado distinto a la situación de guerra, aunque puede estar conectado con ella. El problema reside en la naturaleza y el alcance de esa conexión, pues, frente al estado de sitio, instituto cuyos presupuestos, efectos y límites han sido tasados, la "guerra" es una noción carente en nuestro ordenamiento de definición jurídica.

El artículo 63.3 de la CE alude a la declaración de guerra, que atribuye solemnemente al Rey, previa autorización de las Cortes, pero no especifica los supuestos en que procede, ni la conecta con los estados excepcionales del artículo 116 de la CE, ni con las funciones de las Fuerzas Armadas. Alguna doctrina ha considerado la guerra formalmente declarada como un supuesto más de derecho excepcional por cuanto presupone una situación grave y tiene un estatuto jurídico específico, aunque muy limitado, contenido sumariamente en los artículos 15, 63.3 y 169 de la $C^{14}$. En mi opinión, sin embargo, la guerra, pese a representar materialmente la situación más comprometida para la soberanía estatal, ha quedado en la más absoluta penumbra jurídica; una penumbra que no contribuye a esclarecer una pretendida lectura conjunta de los referidos preceptos constitucionales.

Supuestamente, los artículos 15 y 169 de la CE regularían alguno de los efectos del estado declarado de guerra, cuales son la eventual suspensión de la abolición de la pena de muerte y la prohibición de iniciar una reforma constitucional durante el conflicto, pero, en realidad, las expresiones "tiempos de guerra" y "tiempo de guerra" contenidas, respectivamente, en dichos preceptos tienen distinto significado que la declaración de guerra a que alude el artículo 63.3 de la CE,

13 R. MAteu-Ros y Cerezo, "Estados de alarma, excepción y sitio», en VV.AA.: Gobierno y Administración en la Constitución, vol. I, Instituto de Estudios Fiscales, Madrid, 1988, p. 181.

14 P. CRuz Villalón, "La protección extraordinaria del Estado", en E. García dE ENterría y A. Predieri (dirs.), La Constitución española de 1978. Estudio sistemático, Civitas, Madrid, 1980, p. 675; A. TORRes Del Moral, Principios de Derecho Constitucional español, Servicio de Publicaciones de la Facultad de Derecho de la Universidad Complutense, Madrid, 1992, p. 650; Y. GóMEZ SÁNCHEZ, «La pena de muerte (art. 15)", Revista de Derecho Político, núm. 36, 1992, pp. 183-185, y J. PéREz Royo, "Artículo 169. Límites a la reforma constitucional», en O. AlzAGA VILLAAMIL (dir.), Comentarios a la Constitución española de 1978, tomo XII, Edersa-Cortes Generales, 1999, pp. 512-513. 
por lo que no cabe realizar una interpretación coincidente ${ }^{15}$. En el ordenamiento y la práctica internacionales, la declaración de guerra es, además, una fórmula en desuso a la que los Estados no suelen recurrir para evitar imputaciones de agresión internacional ${ }^{16}$. Nuestro constituyente incurrió en el anacronismo de referirse a ella, pero al menos no cometió el error de vincularla con las expresiones "tiempo" o "tiempos" de guerra, alusivas, en nuestra opinión, a cualesquiera situaciones materialmente bélicas en que España se halle inmersa en defensa de su integridad territorial o en cumplimiento de sus obligaciones internacionales, para las que la declaración de guerra no resulta

15 Aunque la expresión "tiempos de guerra» del artículo 15 de la CE fuera interpretada restrictivamente, haciéndola coincidir con la declaración jurídica de guerra, dicha interpretación no tendría que ser necesariamente extensible a la expresión "tiempo de guerra" contenida en el artículo 169 de la CE. Y es que, a pesar de la identidad de términos, la finalidad que persigue este último precepto (que la reforma de la Constitución no se inicie en un momento de anormalidad) aconsejaría interpretarla en un sentido amplio. Si un simple estado de alarma declarado en una provincia supone la imposibilidad de iniciar el procedimiento de reforma, la existencia de hostilidades generalizadas en las que nuestro país participe debiera implicar idéntica prohibición, puesto que la situación de anormalidad se daría de igual forma, fuera o no reconocida por el Derecho, existiera o no declaración formal de guerra ex artículo 63.3 de la CE. En este sentido, C. GARRIDO LóPEZ, "Las funciones constitucionales de las Fuerzas Armadas y su ejercicio", Cuadernos de la Cátedra Fadrique Furió Ceriol, núms. 11-12, 1995, pp. 200-201, y L. Сotino HuEso, El modelo constitucional de las Fuerzas Armadas, Centro de Estudios Políticos y Constitucionales, Madrid, 2002, pp. 222-228.

16 En el Derecho Internacional no existe norma alguna que vincule necesariamente el recurso a la fuerza con la declaración formal de hostilidades, decisión que, además, se desplaza de los Estados miembros de las Naciones Unidas al Consejo de Seguridad o, incluso, a la Asamblea General de la Organización. El artículo 51 de la Carta de las Naciones Unidas permite a los Estados responder a un ataque o agresión armada en legítima defensa sin necesidad de previa declaración de guerra "hasta tanto que el Consejo de Seguridad haya tomado las medidas necesarias para mantener la paz y la seguridad internacionales", lo que, unido a la proscripción de la guerra ofensiva contenido en su artículo 2.4, conduce, en la práctica, a la presentación de cualquier acto bélico de un país contra la soberanía e integridad territorial de otro como defensivo o necesario para su seguridad, aunque no lo sea en absoluto, no existiendo nunca por parte del agresor ni del agredido declaración formal de guerra. Sobre la obsolescencia de la declaración de guerra, J. GARCÍA FERNÁNDEZ, "Guerra y Derecho Constitucional», Cuadernos Constitucionales de la Cátedra Fadrique Furió Ceriol, núm. 32, 2000, pp. 44-46, y E. PÉREZ VerA y A. J. Rodríguez Carrión, "Artículo 63. Atribuciones del Rey», en O. Alzaga VilLAamil (dir.), Comentarios a la Constitución española de 1978, tomo V, Edersa-Cortes Generales, Madrid, 1997, pp. 276-278. 
precisa $^{17}$. No en vano, la Ley Orgánica 13/1985, de 9 de diciembre, del Código Penal Militar, distinguió expresamente dichas locuciones, incluyendo la guerra formalmente declarada en la noción, internacionalmente considerada más amplia, de "tiempo de guerra". "A los efectos de este Código — proclama su artículo 14- se entenderá que la locución "en tiempo de guerra" comprende el período de tiempo que comienza con la declaración formal de guerra, al ser decretada la movilización para una guerra inminente, o con la ruptura generalizada de hostilidades con potencia extranjera, y termina en el momento en que cesen éstas".

Aunque la declaración de guerra resulte inusual, formalmente, al menos, el estado de sitio podrá coincidir con una situación de guerra declarada como medida superpuesta y adicional a las decisiones estrictamente bélicas. $Y$ también podrá coincidir, materialmente, con la ruptura generalizada de hostilidades propia de los "tiempos de guerra". Ambos supuestos bélicos, conceptual y constitucionalmente distintos como acabo de referir, no producirán, sin embargo, otros efectos jurídicos adicionales a los de la declaración del estado de sitio con la que coincidan que los expresamente previstos en los artículos 15 y 169 de la CE.

En situaciones de guerra defensiva, única permitida por el artículo 2.4 de la Carta de las Naciones Unidas, resulta difícilmente concebible que el Estado pueda prescindir de los recursos y medidas internas que el derecho de excepción habilita, por lo que lo normal será que la guerra - formal o no-y el estado de sitio coexistan ${ }^{18}$. Este estado, empero, no siempre y necesariamente estará conectado a situaciones bélicas, pudiendo ser verdaderamente "ficticio" cuando su declaración trate de preservar el ordenamiento constitucional o la integridad territorial de agresiones o amenazas violentas de orden interno que no impliquen el enfrentamiento militar abierto y generalizado característico de la guerra. El estado de sitio ampara, en fin, entre sus presupuestos habilitantes todas la crisis bélicas, declaradas formalmente o no, que puedan amenazar los fundamentos del Estado; dada su naturaleza política, sin embargo, no excluye otras emergencias distintas de la guerra — declarada

17 En este sentido, R. MATEU-Ros Y CEREzo, "Los estados de alarma, excepción y sitio", cit., p. 182; C. CONDE-PUMPIDO FERREIRO, "Estado de sitio y tiempos de guerra», en VV. AA., Gobierno y Administración en la Constitución, vol I, cit., p. 430-432, y F. SANTAOLALla LÓPEZ, "Comentario al artículo 169", en F. GarRido Falla (dir.), Comentarios a la Constitución, cit., pp. 2750-2751.

18 C. Conde-Pumpido FerReIRo, "Estado de sitio y tiempos de guerra», cit., p. 435. 
o no- que pongan igualmente en grave riesgo los citados fundamentos $^{19}$.

Lo cierto, en cualquier caso, es que el estado de sitio constituye el "techo" máximo de nuestro ordenamiento constitucional por lo que a su adaptación a las circunstancias se refiere. Es el último recurso institucionalmente previsto frente a amenazas violentas, insurrecciones o actos de fuerza, "incluido el supuesto de guerra exterior formalmente declarada y [...] el de una situación interior que no pudiese ser descrita sino como guerra civil ${ }^{20}$, para los que no existe regulación jurídica específica en la CE. Y agota, en fin, nuestro derecho de excepción, más allá del cual no cabe sino la suspensión de la abolición de la pena de muerte (art. 15 de la CE), por otra parte desactivada mediante Ley Orgánica 11/1995, de 27 de noviembre, de abolición de dicha pena también en "tiempo de guerra».

\section{BANDOS MILITARES Y PRINCIPIO DE LEGALIDAD PENAL. ÁMBITO DE LA JURISDICCIÓN CASTRENSE EN EL ESTADO DE SITIO}

El bando militar, la represión armada y los consejos de guerra, constituidos para juzgar y condenar sumariamente, integraron el ritual característico de los estados de sitio ficticios declarados en nuestro país, desde la primera guerra carlista hasta el estado de guerra de octubre de 1939. Tras la aprobación de la Constitución y de la LOAES las cosas han cambiado sensiblemente. La omnipotencia de las autoridades militares en tiempos de crisis ha dado paso a la supremacía del poder civil. Y, consecuentemente, la competencia para declarar el estado de sitio, la naturaleza de los bandos y el alcance de la jurisdicción militar han experimentado modificaciones sustantivas ${ }^{21}$.

19 En este sentido, R. MATEU-Ros y CEREZo, "Estados de alarma, excepción y sitio», cit., p. 181. Asimismo, J. GARCíA FERNÁNDEZ, "El Parlamento y la guerra. La posición de las Cortes Generales ante las misiones militares en el exterior", Asamblea. Revista parlamentaria de la Asamblea de Madrid, núm. 8, 2003, p. 150.

20 P. CRuz Villalón, «El nuevo derecho de excepción», cit., pp. 101-102.

21 Frente a quienes consideran que los cambios operados han "desnaturalizado» el estado de sitio, P. CRUz VILLALón prefiere hablar de discontinuidad respecto de su original decimonónico, surgido cuando «el nivel de desarrollo de las comunicaciones y la misma estructura del poder estatal no permitían excluir situaciones en las que la organización militar era la única capaz de asumir eficazmente, en un determinado territorio, las funciones estatales». Estados excepcionales y suspensión de garantías, cit., pp. 128-129. 
El estado de sitio ya no se declara mediante bando militar, ni por decisión de la autoridad civil local, sino por resolución del Congreso de los Diputados, a propuesta exclusiva del Gobierno. El beneficiario del poder excepcional tampoco es la autoridad militar, autónomamente, sino la autoridad civil, cuya posición y poder durante el estado de sitio no se debilita, ni cede. El Gobierno, que dirige la política militar y de la defensa conforme al artículo 97 de la $C E$, asume en virtud de la declaración todas las facultades extraordinarias previstas en la CE y en la LOAES. A él compete dirigir y administrar el estado de sitio, aunque, atendiendo a la naturaleza violenta de la amenaza, debe designar «la autoridad militar que, bajo su dirección, haya de ejecutar las medidas que procedan en el territorio a que el estado de sitio se refiera" (art. 33.2 de la LOAES). El Ejército se convierte de este modo en instrumento; en un mero gestor necesario de la crisis, al que las autoridades civiles no se someten por la mera declaración de la emergencia sino en la medida en que el Congreso de los Diputados prevea o el Gobierno autorice. "Las autoridades civiles continuarán en el ejercicio de las facultades que no hayan sido conferidas a la autoridad militar de acuerdo con la presente ley», señala el artículo 36 de la LOAES, confirmando que la asunción militar de facultades no se produce ipso iure, como posibilitaba el artículo 22.2 de la Ley Orgánica 6/1980, de 1 de julio, sobre Criterios Básicos de la Defensa Nacional, hoy derogada por la Ley Orgánica 5/2005, de 17 de noviembre, de Defensa Nacional. Ahora bien, una vez decidida y delimitada, dicha asunción de facultades debe regirse por «los criterios de autonomía indispensables para que las Fuerzas Armadas ejerzan la función conminatoria que probablemente requiera el enfrentamiento a esta clase de situaciones» ${ }^{22}$.

Sustituyendo al legislador, la autoridad militar dictaba durante los estados de guerra de nuestro pasado una normativa penal de "emergencia" bajo el nombre de bando que derogaba temporalmente las leyes penales vigentes. El tradicional bando no suspendía derechos, medida reservada constitucionalmente a los estados excepcionales de naturaleza civil, pero creaba tipos delictivos, agravaba penas y extendía el ámbito de los procedimientos militares sumarios. Tras su reforma por Ley Orgánica 9/1980, de 6 de noviembre, el artículo 6.8 del Código de Justicia Militar de 1945 siguió permitiendo la tipificación y sanción de conductas delictivas mediante bando, previa declaración del estado de $\operatorname{sitio}^{23}$. Y la propia LOAES, en lugar de prohibir expresamente esta

22 R. Mateu-Ros y Cerezo, "Estados de alarma, excepción y sitio», cit., p. 184.

${ }^{23}$ Fue lo que hizo, de hecho, el capitán general de la III Región Militar, teniente general Milans del Bosch, con ocasión del frustrado intento de golpe de Estado de 
especie de "ley penal en blanco", se refiere ambiguamente a los bandos, "que contendrán las medidas y prevenciones necesarias, de acuerdo con la Constitución, la presente ley y las condiciones de la declaración del estado de sitio" (art. 34). Aunque el precepto resulta desacertado, parece evidente que, interpretado conforme a la Constitución, no cabe competencia legislativa alguna de la autoridad militar sobre la materia, pues sólo el Gobierno está habilitado para dictar disposiciones provisionales con fuerza de ley, con las limitaciones materiales prefijadas en el artículo 86.1 de la CE. Los bandos militares, por tanto, ya no pueden ser "ordenanzas de necesidad", como los caracterizara Rodríguez Devesa ${ }^{24}$, ni establecer delitos o penas distintos a los legalmente prefijados. Proclamado inconcusamente el principio de legalidad en materia penal en el Código Penal Militar de 1985, los bandos contendrán a lo sumo instrucciones recordatorias y admonitorias acerca de los tipos (comunes o militares) aplicables durante el estado de sitio, pero nada más. Y ni siquiera la resolución declaratoria del Congreso de los Diputados podría convertirlos en otra $\operatorname{cosa}^{25}$.

La extensión de la jurisdicción militar a ámbitos no estrictamente castrenses sigue siendo, en cambio, uno de los rasgos característicos del estado de sitio. Dicha extensión, sin embargo, no es automática, sino potestativa y supeditada a mención expresa. «En la declaración del estado de sitio el Congreso de los Diputados podrá determinar los delitos que durante su vigencia quedan sometidos a la jurisdicción militar», proclama el artículo 35 de la LOAES. La sustracción del conocimiento de determinados delitos a la jurisdicción ordinaria y su

23 de febrero de 1981, en su célebre bando, con el que, contraviniendo el tenor del artículo 116.4 de la CE y amparándose en la ausencia de desarrollo legal del mismo, proclamó un estado de sitio ficticio en el territorio bajo su mando; estado durante el cual, según indicaba el artículo 3 del referido bando, quedarían "sometidos a la jurisdicción militar y tramitados por procedimientos sumarísimos" las agresiones contra edificios, establecimientos, vías de comunicación y transporte, servicios de agua, luz y electricidad y almacenes de primera necesidad, "así como los delitos de rebelión, sedición y de atentado o resistencia a los agentes de la autoridad. Los de desacato, injuria, amenaza o menosprecio a todo el personal militar o militarizado que lleve distintivo, cualquiera que lo realice, propague, incite o induzca. Igualmente, los de tenencia ilícita de armas o cualquier otro objeto de agresión".

24 J. M. a Rodríguez DeVESA, "Bandos penales militares», Revista Española de Derecho Militar, núm. 3, 1957, p. 157.

${ }^{25}$ R. MATEu-Ros y Cerezo, "Estados de alarma, excepción y sitio», cit., p. 186. En idéntico sentido, F. FERNÁNDEZ SEGADO, "La función de las Fuerzas Armadas en el estado de sitio...", cit., pp. 244-246, y J. M. SeRRANo AlberCA, "Comentario al artículo $116 »$, cit., pp. 1802-1803.

(C) UNED. Revista de Derecho Político 
atribución a la militar dependerá de las circunstancias apreciadas libremente por el Congreso de los Diputados, lo que constituye un acierto. El problema es que, conforme al tenor del citado precepto, también resulta discrecional la determinación ad hoc del propio alcance de la jurisdicción militar fuera del ámbito castrense, tarea que, de conformidad con el artículo 117.5 de la CE, debiera haberse acometido directamente mediante ley. El progreso, con todo, resulta notable. La ampliación de la jurisdicción militar ha dejado de ser consustancial al estado de sitio $y$, al tiempo, se ha privado a la autoridad militar de toda competencia sobre la materia, sin que la expresión "podrá determinar», contenida en el artículo 35 LOAES y referida a la declaración parlamentaria, pueda ser interpretada en beneficio del clásico bando, "en el sentido de que se está aludiendo a una mera posibilidad de explicitación que en el supuesto de no producirse [...] entraña como efecto directo que la autoridad militar quede con total autonomía para decidir al respecto lo que estime pertinente ${ }^{26}$. Al contrario. De acuerdo con dicha expresión, corresponde al Congreso de los Diputados decidir si es necesario o no extender el ámbito de la jurisdicción castrense, quedando vinculada la autoridad militar a la decisión adoptada sin que los bandos puedan prescribir incremento de competencia jurisdiccional alguna.

\section{EFECTOS SOBRE EL RÉGIMEN JURÍDICO DE LAS LIBERTADES Y EL ESTATUTO ORDINARIO DEL PODER}

El artículo 55.1 de la CE enuncia con indudable carácter de numerus clausus los derechos fundamentales y libertades públicas cuyo ejercicio puede ser suspendido bajo los estados de excepción y sitio. El resto es resistente a la excepción, no pudiendo ser objeto de suspensión por grave que resulte la emergencia, como se encarga de subrayar el artículo 13.2.a) de la LOAES. Consecuentemente, la suspensión de los derechos fundamentales de libertad personal, inviolabilidad de domicilio, secreto de las comunicaciones, libertad de expresión e información, libre circulación, reunión, manifestación y huelga puede formar parte de "las condiciones" del estado de sitio declarado, a los que cabe añadir la suspensión temporal de las garantías jurídicas del detenido reconocidas en el artículo 17.3 de la CE. Y ello, aunque, como señala Requejo Rodríguez, resulte difícilmente explicable cómo puede ayudar al restablecimiento de la normalidad la privación al detenido de la asistencia le-

${ }^{26}$ F. Fernández Segado, "La función de las Fuerzas Armadas en el estado de sitio, en el marco de la Constitución de 1978», cit., p. 248. 
trada, la ocultación de los motivos de su detención o que pueda obligársele a declarar cuando el artículo 15 de la CE continúa en todo caso vigente $^{27}$.

Así las cosas, el obligado respeto en situaciones de normalidad al contenido esencial de los derechos fundamentales puede ceder con ocasión de una crisis declarada. Ello desconstitucionaliza en cierta medida el contenido de los derechos ampliando correlativamente el margen de libertad del legislador de excepción, pero no afecta a su condición de derechos fundamentales. La suspensión, como subrayara De la Quadra, incide sobre las garantías, que son consecuencia y no causa de la naturaleza fundamental del derecho. La suspensión permite sustituir el régimen jurídico de las facultades vinculadas al objeto; no el objeto mismo, constitucionalmente reconocido y del todo indisponible ${ }^{28}$. La suspensión general de derechos no implica, por tanto, su supresión temporal o su desaparición absoluta durante la vigencia del estado crítico. El reconocimiento constitucional de los derechos subsiste, y con él, la naturaleza fundamental de los mismos. El titular de la decisión de excepción está habilitado para operar una modificación sustancial en su vigencia y en las condiciones de su ejercicio, pero no puede comportarse como si no existieran; ni hacerlos desaparecer del mundo del Derecho, pues continúan presentes en las relaciones entre particulares, al igual que frente al poder público en aquellas circunstancias o ámbitos que nada tengan que ver con la situación excepcional ${ }^{29}$. $Y$ con ser restrictiva, la regulación extraordinaria contenida en la declaración sigue siendo, no obstante, un régimen de legalidad, merced al cual los ciudadanos afectados pueden exigir que la injerencia pública se produzca en los términos normativamente establecidos.

Determinando por remisión el eventual contenido de la declaración del estado de sitio, el artículo 32.3 de la LOAES incorpora lo que la doctrina ha denominado principio de acumulación, en virtud del cual se

27 P. Requejo Rodríguez, "¿Suspensión o supresión de los derechos fundamentales?", Revista de Derecho Político, núm. 51, 2001, pp. 120-121.

28 T. De la Quadra SALCEdo, "La naturaleza de los derechos fundamentales en situaciones de suspensión", Anuario de Derechos Humanos, núm. 2, 1983. Para B. AlÁEZ CorRAL, sin embargo, la suspensión prevista en el artículo 55.1 de la CE representa una auténtica supresión de la vigencia de las normas constitucionales sobre derechos fundamentales más que una mera limitación suspensiva de la eficacia de éstas. Vid. "El concepto de suspensión general de los derechos fundamentales", en L. López GuerRa y E. Espín TeMPLAdo (coords.), La defensa del Estado, Tirant lo Blanch, Valencia, 2004, pp. 242-244.

29 P. REQUejo RodrígueZ, "¿Suspensión o supresión de los derechos fundamentales?», cit., p. 111. 
autoriza al Congreso de los Diputados la adopción de todas las medidas previstas en la LOAES para los estados excepcionales de naturaleza civil -alarma y excepción-, con independencia de la concurrencia de sus presupuestos. Dicha acumulación no se produce, empero, automáticamente, sino en virtud de mención expresa en la declaración correspondiente. De acuerdo con los artículos 16 y siguientes de la LOAES, la "autoridad gubernativa" podrá, de haber sido autorizada, detener a cualquier persona durante un plazo máximo de diez días cuando existan "fundadas sospechas" de su intención de alterar el orden público, quedando obligada tan sólo a comunicar la detención al juez y proporcionarle información sobre la situación del detenido. Suspendido el derecho a la inviolabilidad del domicilio, las inspecciones y registros domiciliarios podrán practicarse, sin consentimiento del titular ni autorización judicial, por la autoridad o sus agentes en presencia de testigos y levantando acta a su término. Para el esclarecimiento de hechos delictivos o el mantenimiento del orden, cabe la intervención de toda clase de comunicaciones, motivándolo por escrito ante el juez. Y también es posible la prohibición de circular o permanecer en horas y lugares determinados, la indicación de itinerarios e identificación obligatoria, la delimitación de zonas de permanencia de protección o seguridad e, incluso, en el caso de personas "peligrosas" para el orden público, la fijación de residencia obligatoria o comunicación preceptiva de todo desplazamiento. Aunque sin censura previa, la suspensión de publicaciones, emisiones, proyecciones cinematográficas y representaciones teatrales está igualmente permitida. La celebración de reuniones y manifestaciones puede requerir autorización previa y, de llevarse a cabo habiendo sido prohibidas, podrían ser disueltas. Las huelgas, en fin, podrían ser prohibidas durante el estado de sitio, lo mismo que cualquier otra medida de conflicto colectivo.

Además de las referidas injerencias y de las sanciones pecuniarias que puedan imponerse conforme a la declaración (art. 13.2.a) y d) de la LOAES), la autoridad beneficiaria de los poderes críticos está habilitada para adoptar una serie de medidas complementarias que no precisan mención expresa. Dichas medidas ejecutivas son, sumariamente, la intervención y control de toda clase de transportes y de la carga de los mismos; las limitaciones al estatuto jurídico de los extranjeros «que se encuentren en España», quienes podrán ser expulsados previa justificación de las razones de orden público que motiven su expulsión; la incautación de armas, municiones y explosivos; la intervención de industrias o comercios que puedan motivar la alteración del orden público, la suspensión temporal de sus actividades y el cierre de locales públicos; la vigilancia y protección de edificios, instalaciones, servi- 
cios públicos e industrias, incluso emplazando puestos armados para ello, así como la totalidad de las medidas previstas para el estado de alarma, desde las limitaciones al uso de servicios y al consumo de primera necesidad, las requisas temporales y la imposición de prestaciones personales obligatorias, hasta la intervención y ocupación de industrias, explotaciones o locales privados y la movilización de su personal.

Sobrevenida la crisis, las derogaciones o adaptaciones del derecho ordinario se regirán, en todo caso, por el principio de proporcionalidad, plasmado en el artículo 1.2 de la LOAES tanto por lo que respecta a las medidas extraordinarias adoptadas en la declaración como a su aplicación y ejecución por los poderes públicos. Concebido como un proceso lógico integrado por sucesivas fases, el principio de proporcionalidad exige la adecuación al fin esencial perseguido, la adopción de la medida menos lesiva y el menor impacto posible en el estatuto jurídico de la normalidad ${ }^{30}$. Las excepciones al derecho ordinario serán, por ello, no todas y cada una de las establecidas por la LOAES para cada estado crítico, sino "las estrictamente indispensables para asegurar el restablecimiento de la normalidad". Y una vez adoptadas en la declaración del estado de sitio, su puesta en práctica habrá de realizarse "en forma proporcionada a las circunstancias» (art. 1.2 in fine de la LOAES).

En virtud de la declaración del estado de sitio, el Gobierno asume todas la facultades extraordinarias autorizadas por el derecho de excepción, pero viene obligado ex artículo 33.2 de la LOAES, a designar la autoridad militar que, bajo su dirección, ejecutará las medidas excepcionales procedentes en el territorio afectado por la declaración. La intervención militar resulta, así pues, legalmente necesaria bajo el estado de sitio. El Gobierno no es libre para designar o no a la autoridad militar, ni puede delegar esa facultad sino ejercerla por sí mismo. En cambio, es plenamente libre para elegir a la autoridad militar correspondiente, que puede estar integrada o no en la cadena de mando del territorio afectado, y designar una o varias cuando el estado de sitio se extienda a todo o buena parte del territorio nacional ${ }^{31}$. A ésta o éstas corresponderá ejecutar la comisión conferida en la declaración, tarea

30 V. Álvarez García, El concepto de necesidad en Derecho Público, Civitas, Madrid, 1996, p. 463.

31 P. CRuz Villalón, Estados excepcionales y suspensión de garantías, cit., p. 118 , y A. Mozo SEOANE, "Estados excepcionales y fuerzas armadas", Boletín de Información del Centro Superior de la Defensa Nacional (CESEDEN), núm. 221, 1991, pp. 20-21. 
que, aun bajo la dirección del Gobierno, cabría desarrollar con un amplio margen de discrecionalidad, sin el que «su función conminatoria sería puramente nominal o semántica", perdiendo eficacia en la acción y desnaturalizándose, con ello, la propia institución en cuanto garantía extraordinaria de la Constitución ${ }^{32}$. La autoridad militar, con todo, no puede recabar para sí facultades de las autoridades civiles que no le hayan sido conferidas en la declaración del estado de sitio o, declarado éste, por el Gobierno. No existe, por tanto, subordinación automática de las autoridades locales al comisionado militar, ni menoscabo de sus facultades ordinarias; tan sólo la obligación de colaborar con aquél en materia de orden público, facilitando cuantas informaciones se soliciten y noticias Ileguen a su conocimiento (art. 36 in fine de la LOAES). Como han precisado los artículos 22 y siguientes de la Ley Orgánica $5 / 2005$, de 17 de noviembre, de Defensa Nacional, durante la vigencia del estado de sitio el sistema de disponibilidad permanente de recursos no propiamente militares y las actuaciones del sistema de cooperación en materia de protección civil serán coordinados por el Consejo de Defensa Nacional -órgano coordinador, asesor y consultivo del Presidente del Gobierno-, al igual que las actuaciones de la Guardia Civil y del Cuerpo Nacional de Policía, fuerzas que dependerán en tal supuesto, respectivamente, de los ministros de Defensa y del Interior, en los términos que determine el Presidente del Gobierno.

Que las Fuerzas Armadas deban intervenir en la gestión de todo estado de sitio, no quiere decir, sin embargo, que éste sea el único cauce operativo para cumplir la misión de defensa del ordenamiento constitucional y de la integridad territorial que el artículo 8.1 de la CE les encomienda. La mayoría de la doctrina condiciona la intervención armada en el interior de España a la declaración del estado de sitio, afirmando, además, que cualquier otra lectura de los artículos 8.1 de la CE y 32.1 de la LOAES «equivaldría a una completa desnaturalización de nuestro régimen constitucional» ${ }^{33}$. En mi opinión, sin embargo,

32 F. Fernández Segado, "La función de las Fuerzas Armadas en el estado de sitio, en el marco de la Constitución de 1978», cit., pp. 242-243.

33 P. CRuz Villalón, «El nuevo derecho de excepción», cit., p. 101. En idéntico sentido, J. M. Serrano Alberca, "Comentario al artículo 8", en F. Garrido Falla (dir.), Comentarios a la Constitución, cit., p. 122; A. PorRAS NADALES, "Ordenamiento de la defensa, poder militar y régimen constitucional en España", Revista de Estudios Políticos, núm. 35, 1983, p. 233; D. LóPEZ GARRIDO, "La posición constitucional de las Fuerzas Armadas", Revista de Administración Pública, núms. 100-102, vol. II, 1983, p. 951; F. FERnÁNDEZ SEGADO, "La función de las Fuerzas Armadas en el estado de sitio, en el marco de la Constitución de 1978", cit., pp. 235-236, y R. BLANCo VALDÉS, La ordenación constitucional de la defensa, Tecnos, Madrid, 1988, pp. 72-74. 
ambos preceptos no proporcionan una base cierta para supeditar el ejercicio de las misiones de las Fuerzas Armadas a la declaración de este estado crítico. El artículo 8.1 de la CE enumera esas misiones, pero, pese a coincidir en su literalidad con los supuestos habilitantes del estado de sitio, no impone un determinado procedimiento para ejercerlas. "Cuando se produzca o amenace producirse una insurrección o acto de fuerza contra [...] la integridad territorial o el ordenamiento constitucional, que no pueda resolverse por otros medios, el Gobierno [...] podrá proponer al Congreso de los Diputados la declaración del estado de sitio", proclama el artículo 32.1 de la LOAES. Y como en ningún momento especifica cuáles serían esos otros medios distintos al estado de sitio con que el Gobierno podría conjurar la amenaza o repeler la agresión, y dicho cometido está atribuido ex Constitucione a las Fuerzas Armadas sin prefijar procedimiento alguno, nada impide que éstas sean utilizadas a iniciativa del Gobierno, con el ordinario control de las Cortes, cuando la suspensión de derechos, la adopción de facultades extraordinarias y la extensión de la jurisdicción militar no sean requeridas por las circunstancias ${ }^{34}$. No en vano, como subraya el propio artículo 1.1 de la LOAES, la declaración de un estado crítico sólo procede cuando el mantenimiento de la normalidad deviene imposible mediante el uso del estatuto ordinario del poder por las autoridades competentes.

Es inconcuso que la declaración del estado de sitio implica la intervención de las Fuerzas Armadas, pero, como admitió Espín Templado, "siempre que no se requieran medidas especiales que superen las atribuciones ordinarias [...], eventualmente, por imposibilidad material de cualquier género, el Gobierno también puede decidir la actuación de las Fuerzas Armadas en cumplimiento de la función que comentamos (la defensa del orden constitucional) sin que el estado de sitio haya sido declarado " ${ }^{35}$. Y de la misma opinión son García Torres y Ruipérez Alamillo, ante el fracaso de otros medios compulsivos, en el caso que concurriera "voluntad desobediente o resistencia" al cumplimiento de las leyes por parte de una Comunidad Autónoma - hipótesis no inverosímil, por cierto, y prevista en el artículo 155 de la CE-, siempre que esa desobediencia no suponga un acto de fuerza y el Congreso de

34 En este sentido, F. LóPEZ RAMón, La caracterización jurídica de las Fuerzas Armadas, Centro de Estudios Constitucionales, Madrid, 1987, pp. 323-324, y C. GARRIDO LÓPEZ, "Las funciones constitucionales de las Fuerzas Armadas y su ejercicio", cit., pp. 202-206.

35 Vid. J. De Esteban, L. López GueRra et alii, El régimen constitucional español, tomo II, Labor, Barcelona, 1982, p. 275. 
los Diputados no estime, por ello, "más idónea y especial» la declaración del estado de sitio $^{36}$.

\section{RESISTENCIAS CONSTITUCIONALES AL PODER DE EXCEPCIÓN}

El estado de sitio no suspende la democracia, por lo que su declaración no puede interrumpir el normal funcionamiento de los poderes constitucionales del Estado, según consignan de forma explícita los artículos 116.5 de la CE y 1.4 de la LOAES. Se garantiza, de este modo, la "resistencia» de la Constitución frente a cualquier modificación o cambio que no se ajuste a las alteraciones competenciales previstas ${ }^{37}$. Y mediante la reiteración de la más relevante fenomenología de esta cláusula general de continuidad, al proclamar la no interrupción de los poderes legislativo y judicial, la impugnabilidad de las disposiciones y actos y la responsabilidad del Gobierno y la Administración, se pretende no sólo que dichos poderes funcionen, sino que lo hagan normalmente, "es decir, - como se subrayó en el proceso constituyente- de acuerdo con las normas, fundamentalmente de acuerdo con la Constitución» ${ }^{38}$.

El artículo 116.5 de la CE prohíbe la disolución del Congreso de los Diputados para salvaguardar el protagonismo parlamentario en situaciones críticas y evitar la excesiva acumulación del poder. Dicha previsión suspende temporalmente la facultad presidencial de disolución, prevista en el artículo 115.1 de la $C E$, lo que, como ha señalado alguna doctrina, podría suponer una contradicción con el principio de mantenimiento del normal funcionamiento de los poderes constitucionales del Estado ${ }^{39}$. Parece, con todo, preferible prescindir de este mecanismo

36 J. García Torres, «El artículo 155 de la Constitución española y el principio constitucional de la autonomía", en VV.AA., Organización Territorial del Estado. Comunidades Autónomas, Instituto de Estudios Fiscales, Madrid, 1984, vol. II, pp. 1280-1281. Más contundente, a favor de la utilización de las Fuerzas Armadas como una de las "medidas necesarias" a adoptar al amparo del artículo 155 de la CE, J. RUIPÉREZ Alamillo, Constitución y autodeterminación, Tecnos, Madrid, 1995, pp. 135142. De similar opinión, L. SÁnCHEZ AgESTA, "La Constitución y las Fuerzas Armadas", en VV.AA., Primeras Jornadas Fuerzas Armadas-Universidad, Madrid, 1982, p. 151, y del mismo autor, Sistema político de la Constitución española de 1978, Editora Nacional, Madrid, 1990, pp. 256-257.

37 R. Mateu-Ros y Cerezo, "Estados de alarma, excepción y sitio", cit, p. 190.

38 Véase la intervención del diputado socialista Pons Irazazabal en el Diario de Sesiones del Congreso de los Diputados, Comisión Constitucional, n. ${ }^{\circ} 160,21$ de abril de 1981, pp. 9892.

${ }^{39}$ F. FERNÁNDEZ SEGADO, "La Ley Orgánica de los estados de alarma, excepción y sitio", cit., p. 91 
de racionalización parlamentaria antes que la representación nacional quede afectada en situaciones críticas ${ }^{40}$. La prohibición de disolución no afecta, en cambio, a los supuestos de disolución automática por irresolución de la investidura presidencial (art. 99.5 de la CE), por aprobación del principio de revisión constitucional (art. 168 de la CE) y por expiración del mandato de los diputados (art. 68.4 de la CE). "La disolución automática propiamente dicha - afirma Bar Cendón-, por su misma esencia, no se puede prohibir o limitar; concebida como consecuencia o efecto jurídicamente necesario de determinados supuestos fácticos, que la propia Constitución prevé de forma expresa, producidos éstos, la disolución automática sigue de forma irremediable. Lo contrario sería una contradicción en sus propios términos, pues no se puede prohibir la producción de un hecho aleatorio, ni, en caso de que éste se produzca, se puede prohibir lo que anteriormente se ha previsto como consecuencia jurídicamente necesaria del mismo ${ }^{41}$. No olvidemos, en efecto, que entre los supuestos de hecho que dan lugar a la activación del procedimiento del artículo 99 de la CE se encuentran la pérdida de la confianza parlamentaria, la dimisión y el fallecimiento del presidente, hipótesis que en absoluto cabe descartar. La prohibición del artículo 116.5 de la CE tampoco incluye la disolución motivada por la aprobación del principio de revisión constitucional si el procedimiento fue iniciado con anterioridad a la declaración del estado de sitio.

Con objeto de evitar la celebración de elecciones con las libertades públicas suspendidas, alguna doctrina ha recurrido al principio de con-

40 "Una alteración puntual y temporal del equilibrio entre poderes -añade $E$. GUILLÉn LóPEZ-, no parece un precio demasiado alto cuando a favor se cuenta con un órgano plenamente representativo para gestionar la crisis". La continuidad parlamentaria: las Diputaciones Permanentes, Civitas, Madrid, 2002, p. 169. Para J.

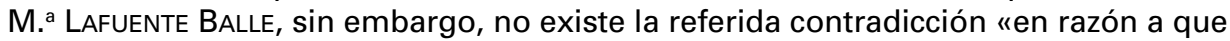
la exigencia de un normal funcionamiento de los poderes establecida en el artículo 1.4 de la Ley Orgánica significa una exigencia de funcionamiento conforme a las normas y a la Constitución. El poder presidencial de disolver las Cámaras funcionará normalmente sólo si cumple toda la normativa constitucional al respecto, y, por tanto, no sólo el artículo 115, sino también el artículo 116.1 de la CE». Cfr. «Los estados de alarma de alarma, excepción y sitio (I)", Revista de Derecho Político, núm. 30, 1989, pp.48-49.

${ }^{41}$ A. BAR Cendón, La disolución de las Cámaras en el ordenamiento constitucional español, Congreso de los Diputados, Madrid, 1989, pp. 239-240. En el mismo sentido, O. Alzaga VillaAmIL, La Constitución española de 1978. Comentario sistemático, Ediciones del Foro, Madrid, 1978, p. 701; R. MATEU-Ros CereZO, "Crisis del Estado y fuentes del Derecho", VV.AA.: La Constitución española y las fuentes del Derecho, vol. II, Instituto de Estudios Fiscales, Madrid, 1979, pp. 1402-1403, y J. M. ${ }^{\text {a }}$ LAFUENTE BALLE, "Los estados de alarma, excepción y sitio (I)», cit., p. 50. 
tinuidad para extender la prohibición de disolución al supuesto de expiración del mandato, que a tal efecto debería ser prorrogado el tiempo que durara la crisis ${ }^{42}$. Esta es una opción frecuente en Derecho Comparado y nuestro legislador no ha dudado en asumirla por lo que a la celebración de referendos se refiere, puesto que el artículo 4.1 de la Ley Orgánica 2/1980, de 18 de enero, sobre regulación de las distintas modalidades de referéndum, prohíbe toda consulta durante la vigencia de los estados de excepción y sitio o en los noventa días posteriores a su levantamiento, quedando incluso suspendida si ya se hubiera convocado. Los artículos 68.4 y 69.6 de la CE dificultan, sin embargo, una solución análoga en el supuesto de expiración del mandato de los diputados. Su redacción es taxativa y, a diferencia del Proyecto de Constitución aprobado en el Congreso, cuyo artículo 109.5 establecía su prórroga hasta tanto la situación crítica permaneciera ${ }^{43}$, en ningún caso está previsto que la legislatura dure más de cuatro años, por lo que disueltas las Cámaras por ese motivo la convocatoria de elecciones se impone $^{44}$. Lo importante, no obstante lo anterior, es que, aun disuelto el Congreso automáticamente, el protagonismo parlamentario está en todo momento garantizado, pues, de acuerdo con los artículos 116.5 in fine de la CE y 165.2 del Reglamento de la Cámara, la Diputación Permanente asume durante los estados críticos todas las competencias del Pleno en esta materia ${ }^{45}$.

Aunque el Senado no desempeña ninguna tarea específica bajo el estado de sitio, también puede controlar políticamente la gestión de la

42 En este sentido, I. Molas e I. PITARCH, Las Cortes Generales en el sistema parlamentario de Gobierno, Tecnos, Madrid, 1987, p. 59; J. A. Alonso DE ANTONIO, "La Diputación Permanente en el sistema constitucional español», Revista de las Cortes Generales, núm. 1986, p. 180, y F. SANTAOLALLA LóPEZ, Derecho parlamentario español, cit., p. 93, para quien la "prórroga de la legislatura, producida ope legis, sólo se mantiene mientras dure la vigencia de los estados de anomalía en la vida estatal. Concluidos éstos, debe entenderse caducado el mandato prorrogado y, en consecuencia, han de convocarse nuevas elecciones".

43 Boletín Oficial de las Cortes, Congreso de los Diputados, núm. 135, 24 de julio de 1978, p. 2964.

${ }^{44}$ En opinión de P. CRuz VilLalón, el constituyente tuvo que optar entre el riesgo que suponía no prorrogar la legislatura haciendo necesario convocar y celebrar elecciones con las garantías suspendidas y el riesgo de que una mayoría recurriera a la declaración de un estado excepcional "a fin de evitar la celebración de unas elecciones en las que podría perder su condición de tal». Estados excepcionales y suspensión de garantías, cit., p. 134.

45 Sobre el ámbito funcional de las Diputaciones Permanentes en relación con los estados críticos, E. GUILLÉn LÓPEZ, La continuidad parlamentaria: las Diputaciones Permanentes, cit., pp. 171-176. 
crisis. Su disolución voluntaria no ha sido prohibida, pero no parece que la anormalidad constitucional sea un contexto oportuno para proceder a ella, celebrar elecciones y alterar, eventualmente, su composición. Si el constituyente prohibió tan sólo la disolución del Congreso se debió a su protagonismo en estas situaciones, no a una voluntad manifiesta de excluir al Senado de dicha prohibición. De ahí que la mayoría de la doctrina afirme el principio de indefectibilidad del Senado al amparo del principio general de continuidad de los poderes constitucionales del Estado ${ }^{46}$.

La declaración del estado de sitio no modifica "el principio de responsabilidad del Gobierno y sus agentes reconocidos en la Constitución y en las leyes", proclama el artículo 116.6 de la CE, excluyendo de este modo toda convalidación parlamentaria ex post facto de las acciones gubernamentales ilegítimas y, en general, el recurso a los bills of indemnity característicos del constitucionalismo británico, en alguna ocasión importados a nuestro país (v.gr. la ley de indemnidad de 10 de enero de 1877) ${ }^{47}$. El principio de necesidad apreciado por los tribunales de justicia podría llegar a justificar jurídicamente una actuación desproporcionada o ilegal de los poderes públicos en la crisis $^{48}$, pero en los regímenes constitucionales modernos, donde la soberanía parlamentaria ha dado paso a la supremacía constitucional, en absoluto cabe hacerlo políticamente mediante exoneración parlamentaria.

Corolario del principio de responsabilidad, el artículo 3.1 de la LOAES proclama la justiciabilidad e impugnabilidad de los actos y disposiciones de la Administración Pública "de conformidad con lo dispuesto en las leyes". Durante la vigencia del estado de sitio el Poder Judicial continúa ejerciendo sus funciones bajo el principio de unidad jurisdiccional, sólo alterado, eventualmente, por la extensión del ámbito

46 P. CRuz Villalón, "La protección extraordinaria del Estado», cit., p. 676, y, del mismo autor, Estados excepcionales y suspensión de garantías, cit., p. 132. Asimismo, A. BAR CENDÓN, La disolución de las Cámaras en el ordenamiento constitucional español, cit., pp. 241-242. En contra de esta tesis, J. M. ${ }^{a}$ LAFUENTE BALLE, "Los estados de alarma, excepción y sitio (I)", cit., p. 49.

47 Atendiendo a las extraordinarias circunstancias que, desde enero de 1874 hasta la reunión de las nuevas Cortes, había atravesado el país, el artículo 1 de la Ley de 10 de enero de 1877 "declara libres de toda responsabilidad a los Gobiernos que se han atribuido y ejercido, durante el indicado período de tiempo, facultades legislativas en el orden político". Citado en F. FERnÁNDEZ SEGADO, El estado de excepción en el Derecho constitucional español, cit, pp. 103-104.

48 V. Álvarez García, El concepto de necesidad en el Derecho Público, cit., pp. 100-123. 
de la jurisdicción castrense. Consecuentemente, los ciudadanos disponen de todos los recursos ordinarios de tutela judicial de derechos, entre los que destacan de modo especial el recurso preferente y sumario o amparo ordinario de derechos fundamentales y el amparo constitucional. Y si, como consecuencia de la aplicación de actos y disposiciones extraordinarios, algún ciudadano sufre en su persona, derechos o bienes, daños o perjuicios que no le sean imputables, tendrá derecho a ser indemnizado, según subraya el artículo 3.2 de la LOAES, incluyendo en su ámbito tanto el supuesto de indemnización por acto lícito como el de responsabilidad por acto culposo, doloso o de riesgo. La responsabilidad patrimonial exigirá, sin embargo, la producción de un daño o perjuicio efectivo, individual y económicamente evaluable consecuencia necesaria o efecto directo del acto o disposición del Gobierno o sus agentes, sin que haya mediado fuerza mayor ni imputabilidad a cargo de la víctima o de un tercero ${ }^{49}$. El fundamento de la reclamación de responsabilidad de la Administración se halla en el artículo 102 de la CE, si deriva de acciones tipificadas como delito, y en el artículo 106.2 de la CE, si la responsabilidad es civil como consecuencia del funcionamiento de los servicios públicos. Al juez corresponderá, en cualquier caso, apreciar la existencia de responsabilidad y la cuantía de la indemnización.

Junto a las garantías jurisdiccionales de derechos, también se mantienen durante el estado de sitio las garantías orgánicas, como el Defensor del Pueblo o los comisionados parlamentarios autonómicos, cuya actividad no se interrumpe, ni tampoco el derecho de las personas afectadas para acceder a ellos, sin perjuicio de lo establecido en los artículos 55 y 116 de la CE y en las leyes que desarrollan estas instituciones, como señalan los artículos 11.3 de la Ley Orgánica 3/1981, de 6 de abril, del Defensor del Pueblo, y 1.4 de la Ley 36/1985, de 6 de noviembre, por la que se regulan las relaciones entre el Defensor del Pueblo y las figuras similares en las distintas Comunidades Autónomas.

Durante la vigencia del estado de sitio, el artículo 169 de la CE prohíbe cualquier iniciativa de reforma constitucional. Se trata, obviamente, de una garantía más frente a la excepción, aunque en este caso no consiste en asegurar el normal ejercicio del poder de revisión, sino en su limitación mientras persista la crisis. La razón para ello es clara, pues, como señaló la doctrina, iniciar una reforma de la Constitución "con un poder excesivamente potenciado [...] implica la posibilidad

49 J. M. Serrano Alberca, "Comentarios al artículo 116», cit., pp. 1815-1817, y R. MATEU-Ros y CeREzo, "Estados de alarma, excepción y sitio», cit., pp. 196-197. 
de una ruptura definitiva del equilibrio de la misma, al poder ser una reforma realizada únicamente en función de la causa determinante de la situación de anormalidad constitucional» ${ }^{50}$.

A tenor del referido precepto, el poder de revisión debe abstenerse de emprender una reforma de la Constitución en situaciones críticas, pero no, al parecer, de proseguir con el procedimiento de reforma si éste estuviese en marcha. Semejante paradoja es fruto de una enmienda in voce del Grupo Parlamentario Comunista, cuya aceptación limitó al alcance del precepto a fin, según se dijo, de evitar que la declaración de alguno de los estados excepcionales sirviera para bloquear una reforma en marcha ${ }^{51}$. La precaución, sin embargo, resulta absolutamente innecesaria, puesto que, a excepción del estado de alarma, que puede ser declarado por el Gobierno, el Congreso interviene tanto en la declaración o prórroga de los estados excepcionales como en la aprobación de la reforma constitucional, por lo que bastaría oponerse a ésta sin necesidad de recurrir al derecho de excepción ${ }^{52}$. Prohibido o no expresamente por el artículo 169 de la CE, lo cierto es que la declaración de la crisis debiera implicar la suspensión de todo trámite de reforma, tal y como preveía el precepto originario, a fin de subrayar con esa actitud la "resistencia» de la Constitución a la excepción y la firme voluntad de defenderla hasta que la normalidad sea restablecida ${ }^{53}$.

50 I. Berdugo Gómez de LA TORRE, "Garantías en la Constitución ante la suspensión de derechos fundamentales", Sistema, núm. 42, 1981, p. 72.

51 Véase la intervención del diputado comunista Solé Tura en el Diario de Sesiones del Congreso, Comisión de Asuntos Constitucionales y Libertades Públicas, núm. 93, 20 de junio de 1978, pp. 3477-3478.

52 «Si la reforma constitucional gravita en las Cámaras -afirma perplejo DE VEGA GARCíA-, y si la declaración y continuidad de los estados de excepción, según el artículo 116, también depende de ellas, no se sabe ciertamente qué es, ni ante quién, lo que se quiere asegurar. Lo lógico es pensar que si las Cámaras se deciden por la declaración de situaciones de excepción no se decidan por la reforma, y a la inversa». Cfr. La reforma constitucional y la problemática del poder constituyente, Tecnos, Madrid, 19985, p. 162. Igualmente, F. SANTAOLALLA LÓPEZ, "Comentario al artículo 169", en F. GARRIDo FALLA (dir.), Comentarios a la Constitución, cit., p. 27512752, y P. CRUz VILLALÓN, Estado excepcionales y suspensión de garantías, cit., pp. 136-137.

53 En este sentido, J. PÉREz RoYo, La reforma de la Constitución, Congreso de los Diputados, Madrid, 1987, p. 154, y F. SANTAOLALLA LÓPEZ, "Comentario al artículo 169 ", cit., p. 2752, quien proclama abiertamente la incompatibilidad entre los estados de anomalía y cualquier proceso de reforma constitucional. 


\section{PROCEDIMIENTO DE DECLARACIÓN, PRÓRROGA Y CESE}

La declaración del estado de sitio ha dejado de ser una facultad del Gobierno o de las autoridades locales, civiles o militares ${ }^{54}$, para atribuirse en todo caso al Congreso de los Diputados, decidida por mayoría absoluta de sus miembros (art. 116.4 de la CE). Esta opción resulta coherente con nuestro sistema parlamentario de gobierno. Y, al distinguir entre beneficiario y titular de los poderes extraordinarios, refuerza las garantías que rodean la suspensión de derechos y la concentración de poderes, incluso, como sostienen algunos de sus críticos, en detrimento de la eficacia y la inmediatez de la respuesta del Estado, que aconsejaban atribuir la decisión de declarar el estado crítico al Ejecutivo ${ }^{55}$.

A diferencia de la prórroga del estado de alarma y de la declaración del estado de excepción, la intervención gubernamental en el procedimiento declarativo del estado de sitio ha quedado reducida a su "apertura». La preceptiva propuesta del Gobierno, sin embargo, excluye que la iniciativa pueda surgir de la propia Cámara, lo que, unido a la estrecha relación fiduciaria previsiblemente existente entre el Gobierno y la mayoría parlamentaria, otorga a éste una posición de predominio operativo que reduce la posibilidad de una divergencia de pareceres ${ }^{56}$. De ahí que algún autor haya criticado la mayoría parlamentaria exigida para la declaración, a su entender insuficiente para garantizar que la

${ }^{54}$ En la Ley de Orden Público de 1870, la declaración del estado de guerra correspondía al Gobierno «en la capital de la Monarquía y puntos donde residan el Rey o la Regencia del Reino" (art. 15), pudiendo ser declarado en el resto por las autoridades locales y ratificado posteriormente por el Gobierno (art. 13). En la Ley de Orden Público de 1933 la intervención del Gobierno era precisa si el estado afectaba a la capital de la República o a todo el territorio de una región autónoma (arts. 52 y 59), pudiendo tomar la iniciativa las autoridades locales en el resto de supuestos (art. 48). Bajo la Ley de 1959, en fin, la declaración debía ser acordada por el Gobierno, mediante decreto-ley, pero por razones de urgencia también los gobernadores civiles y las autoridades locales podían declararlo, dando cuenta al Gobierno con posterioridad (arts. 36 y 37).

${ }^{55}$ En este sentido, O. Alzaga VILlaAmIL, Comentario sistemático a la Constitución española de 1978, Ediciones del Foro, Madrid, 1978, p. 699; F. FERnÁNDEZ SEGADO, "La Ley Orgánica de los estados de alarma, excepción y sitio", cit., pp. 103, y F. SANTAOLALLA LóPEZ, Derecho parlamentario español, Espasa-Calpe, Madrid, 1990, pp. 373374 , para quien el procedimiento resultante de este protagonismo parlamentario se caracteriza «por un fárrago, lentitud y complicación innecesarios. Es más, y esto es lo más importante, tiene el riesgo de que los estados de alarma, excepción y sitio resulten impracticables o inútiles para atender las necesidades a que teóricamente deben servir" (nota 23).

56 R. Mateu-Ros y Cerezo, «Estados de alarma, excepción y sitio», cit., p. 183. 
medida más extraordinaria a adoptar por el Estado en su crisis sea fruto del acuerdo entre diversos grupos parlamentarios y no decisión unilateral de la mayoría progubernamental ${ }^{57}$.

En cuanto ley de vigencia latente, la LOAES no resulta directamente aplicable ante una situación crítica, ni se activa automáticamente con la simple declaración de la emergencia. Es tan sólo el "marco normativo" a partir del cual el Congreso de los Diputados constata la crisis y configura el estatuto jurídico del estado excepcional a declarar ${ }^{58}$. A fin de acelerar los trámites, parece lógico que la propuesta del Gobierno, aprobada en Consejo de Ministros, incluya ya el ámbito, la duración y las condiciones de ese estatuto, estructurándose, en palabras de Fernández Segado, como un verdadero "proyecto de declaración» ${ }^{59}$. Comunicada la iniciativa al presidente del Congreso, el asunto ha de ser sometido inmediatamente al Pleno, que será convocado al efecto si no estuviese reunido, incluso en el período entre sesiones. Ajustándose a las previsiones del artículo 162 del Reglamento del Congreso de los Diputados, por remisión de su artículo 164.1, los grupos parlamentarios pueden presentar propuestas alternativas sobre el régimen del estado a declarar hasta dos horas antes del comienzo de la sesión en que la propuesta gubernamental haya de debatirse. Por la importancia de las medidas a adoptar, dichas propuestas deberían pasar por el filtro de las Comisiones, "a fin de ponderarlas con rigor y evitar cualquier decisión impremeditada ${ }^{60}$, pero la necesidad de imprimir celeridad al procedimiento de declaración sacrifica esta garantía. Las propuestas, por tanto, pasan directamente a debate en el Pleno, que comenzará con la exposición de un miembro del Gobierno de las razones que justifican la solicitud de declaración del estado de sitio, continuándose como si se tratara de un debate de totalidad, con turnos a favor y en contra, de quince minutos cada uno, seguidos de las intervenciones de los portavoces de los grupos por un tiempo no superior a diez minutos (art. 112 del Reglamento del Congreso de los Diputados).

Concluido el debate, las diversas propuestas deben someterse a votación, sin que el Reglamento especifique el orden a seguir, ni si la mayoría absoluta exigida ha de obtenerse sobre el conjunto de la iniciativa gubernamental o sobre todas y cada una de sus cláusulas. En re-

57 I. BERdugo Gómez dE LA TORRE, "Garantías en la Constitución ante la suspensión de derechos fundamentales", cit., p. 64.

58 P. CRuz VilLALÓN, «El nuevo derecho de excepción», cit., p. 103.

59 F. Fernández Segado, "La función de las Fuerzas Armadas en el estado de sitio, en el marco de la Constitución española de 1978", cit., p. 238.

60 F. SANTAOlalla LóPEZ, Derecho parlamentario español, cit., pp. 373-374. 
lación con la segunda cuestión, la doctrina considera razonable votar por separado los distintos extremos que conforman la propuesta, en cuyo caso bastaría una mayoría simple para entenderlos aprobados, procediéndose después, al igual que en las leyes orgánicas, a una votación final sobre el conjunto de la declaración. Lo contrario, dificultaría en exceso la adopción de la decisión y, con ello, la adecuada respuesta a la emergencia constitucional ${ }^{61}$.

Declarado el estado de sitio, el presidente del Congreso lo comunicará al presidente del Gobierno, ordenando que se publique la resolución de la Cámara en el Boletín Oficial del Estado. La omisión de toda referencia al Jefe del Estado al término del procedimiento podría hacer pensar en una declaración firmada tan sólo por el presidente del Congreso en aras de la celeridad de su publicación ${ }^{62}$. Es, por otra parte, lo que se viene haciendo en el caso de la convalidación de los decretos-leyes, también realizada mediante resolución del Congreso de los Diputados. En nuestra opinión, sin embargo, la omisión del legislador y la urgencia del procedimiento no deben excluir la sanción regia, refrendada por el presidente del Gobierno, pues no estamos ante una simple resolución de convalidación de una norma ya existente, aunque provisionalmente, y publicada con todas las garantías de procedimiento, sino del establecimiento de un régimen de excepcionalidad constitucional que la firma del Rey debería autentificar y el refrendo del presidente garantizar frente a cualquier manipulación o anomalía en la misma publicación material ${ }^{63}$. "La firma del Rey — afirma García de Enterría- [...], constituye la marca de la supremacía general expresada en el Derecho objetivo y la de su extensión y alcance general y, por tanto, también del mandato de cumplimiento que se incluye a los jueces, a quienes sólo el Rey puede válidamente dirigirse ${ }^{64}$, razones por las que creemos imprescindibles la sanción regia y su posterior refrendo. Para evitar la demora en el trámite, bastaría imprimir la misma celeridad que caracteriza la expedición, refrendo y publicación de los decretos-leyes aprobados por el Gobierno.

61 P. CRuz Villalón, Estados excepcionales y suspensión de garantías, cit., p. 114.

62 Esta es la opinión de A. NAvas CAStillo, "Los estados excepcionales y su posible control por el Tribunal Constitucional», Revista de la Facultad de Derecho de la Universidad Complutense, núm. 87, 1997, p. 155, expresada igualmente en El control jurisdiccional de los actos parlamentarios sin valor de ley, Colex, Madrid, 2000, p. 215.

${ }^{63}$ En este sentido, P. CRUz VILLALÓN, Estados excepcionales y suspensión de garantías, cit., p. 115.

${ }^{64}$ E. García de Enterría y T.-R. Fernández, Curso de Derecho Administrativo, vol.

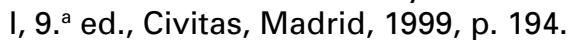


De acuerdo con el artículo 15.3 del Convenio Europeo para la Protección de los Derechos Humanos y de las Libertades Públicas suscrito por España, cuando la declaración del estado de sitio autorice la suspensión de algunos de los derechos reconocidos en el Convenio debe ser comunicada por el Gobierno al Secretario General del Consejo de Europa, a quien se informará de las medidas adoptadas y de los motivos que las inspiraron. Finalizado el período crítico y recuperada la plena vigencia territorial del Convenio, el Secretario General deberá ser igualmente informado.

A diferencia de los estados de alarma y excepción, el estado de sitio carece de limitación temporal expresa. Su duración, que debe determinar el Congreso en el acto de declaración, será la indispensable para asegurar el restablecimiento de la normalidad, como subraya el artículo 1.2 de la LOAES. Transcurrido el plazo fijado en atención a las circunstancias, el estado de sitio cesa automáticamente. La posibilidad de prórroga no ha sido prevista por el legislador, pero parece lógico que, de persistir la gravedad de la emergencia, el Congreso de los Diputados pueda, a propuesta del Gobierno, prorrogar las medidas extraordinarias el tiempo que estime necesario. La modificación de las condiciones del estado declarado durante su vigencia tampoco ha sido prevista, pero nada impide aplicar analógicamente el artículo 15.1 de la LOAES, en el que se autoriza la adopción de medidas distintas de las inicialmente previstas siempre y cuando el procedimiento seguido para introducirlas sea idéntico al de la declaración. Caso de desaparecer las circunstancias que justificaron la declaración o su prórroga antes de transcurrir el plazo establecido, debería procederse al levantamiento anticipado del estado de sitio. La ley, empero, no señala el modo de hacerlo. Y excluida la aplicación analógica del precepto previsto para levantar el estado de excepción (art. 15.2 de la LOAES) por la diferente posición del Gobierno en el procedimiento declaratorio, debería corresponder al Congreso decidir sobre su cese anticipado, aunque a propuesta del Gobierno, a fin de respetar en todo momento el reparto de competencias constitucionalmente establecido.

\section{NATURALEZA JURÍDICA Y CONTROL JURISDICCIONAL DE LAS DECISIONES PARLAMENTARIAS DE DECLARACIÓN Y PRÓRROGA DEL ESTADO DE SITIO}

La declaración del estado de sitio no es tan sólo un acto que constata la emergencia, activando con ello las previsiones de la LOAES. Es una decisión que proclama la crisis, desde luego, pero, además, deter- 
mina y concreta su régimen o estatuto jurídico entre el catálogo de medidas que la LOAES contempla. "[...] en nuestro sistema actual -ha subrayado con acierto Cruz Villalón- la declaración del estado excepcional se configura como un tercer nivel normativo, que viene a sumarse a la LOAES y a la Constitución en el sistema de fuentes del derecho de excepción ${ }^{65}$. La declaración contiene, en efecto, la normativa aplicable durante la vigencia del estado de sitio y constituye fuente de habilitación de disposiciones y actos administrativos. Constata y proclama la emergencia, concretando al tiempo el estatuto extraordinario del poder. Su naturaleza jurídica es, por ello, "borrosa», pues difícilmente cabe caracterizarla conforme a las categorías al uso ${ }^{66}$. Materialmente, la decisión crítica es mitad acto mitad norma. Formalmente, se presenta como una resolución parlamentaria; no es una ley formal, pero, dado su contenido y efectos, tampoco parece que estemos ante un simple acto parlamentario sin alcance normativo.

La declaración del estado de sitio puede incidir sobre la normatividad constitucional suspendiendo su vigencia, aunque también, eventualmente, violándola. "Como toda norma, la Constitución puede ser violada por aquellos que deben cumplirla ${ }^{67}$, particularmente si detentan el suficiente poder para hacerlo, como acontece en situaciones críticas con aquél que las declara. En cuanto titular del poder de excepción, el Congreso de los Diputados, en efecto, podría declarar el estado de sitio sin concurrir los supuestos legalmente previstos para ello, sin alcanzar la mayoría exigida o delegando en la autoridad militar la potestad normativa para tipificar delitos y penas. El Congreso podría, asi-

65 P. CRuz Villalón, «El nuevo derecho de excepción», cit., p. 105.

66 En la teoría de conjuntos y sistemas, alguna doctrina ha empleado la expresión fuzzy ("borroso" o "difuminado») para expresar la idea de que los sistemas lógicos y la pertenencia o adscripción a ellos es cuestión de grado, de intensidad o afinidad de los elementos que se pretenden definir con el modelo o conjunto de referencia (L. A. ZADEH, "Fuzzy Sets», Informations and Control, núm. 8, 1965, pp. 338 y ss.). En la doctrina iusconstitucionalista española esta idea ha sido acogida por $F$. J. BASTIDA FREIJEDO porque siendo, en su opinión, la realidad jurídica borrosa, la teoría que la describa debe articularse, asimismo, con categorías y criterios que permitan una explicación adecuada, sustituyendo la binariedad característica del positivismo lógico por la borrosidad o grado de afinidad entre conceptos jurídicos, normalmente vagos y abstractos, susceptibles, en suma, de variadas concreciones. Vid. "La soberanía borrosa: la democracia», en Fundamentos. Cuadernos monográficos de Teoría del Estado, Derecho Público e Historia Constitucional, núm. 1, 1998, en especial pp. 381-394.

${ }^{67}$ H. KeLSEN, ¿Quién debe ser el defensor de la Constitución?, Tecnos, Madrid, 1995, p. 3. 
mismo, suspender algún derecho fundamental que la Constitución garantiza en todo caso o que, aun permitiendo su suspensión, las circunstancias hacen innecesaria. Y también podría, de primar sobre el derecho la nuda voluntad de poder, decidir alterar el normal funcionamiento de algún órgano constitucional del Estado considerado especialmente molesto para el poder de excepción. La gravedad de estas hipótesis debiera haber llevado al legislador a determinar con precisión las garantías jurisdiccionales existentes frente a ésta y otras decisiones de crisis. Su trascendencia, origen parlamentario y contenido normativo limitaban las posibilidades de sometimiento de la declaración al control de la jurisdicción ordinaria, pero no debiera haber ocurrido otro tanto con la jurisdicción constitucional, cuya vis atractiva es creciente, como evidencian la regulación y la práctica de los principales tribunales constitucionales europeos ${ }^{68}$. La Constitución española, sin embargo, nada indicó al respecto. La LOTC podía haber incluido expresamente estas decisiones entre el elenco de normas y actos susceptibles de declaración de inconstitucionalidad contenido en su artículo 27.2, pero no lo hizo. Y aunque, al amparo del artículo 161.1.d) de la CE, que permite conocer al Tribunal Constitucional «de las demás materias que le atribuyan la Constitución y las leyes", la LOAES podía haberle asignado la competencia para pronunciarse, se limitó a subrayar su inmediata vigencia, publicidad y difusión obligatoria (art. 2 de la LOAES).

Así las cosas, no es extraño que cierta doctrina haya considerado estas decisiones como actos exentos de todo control jurídico, bien por su naturaleza, esencialmente política, por la ausencia de parámetros de referencia adecuados o por la laguna legal existente acerca de su control, que no hallaría "compensación alternativa de ninguna clase" ${ }^{69}$. Sin duda, la declaración de la emergencia es un acto de gran alcance político para el que la Constitución no exige motivación expresa. Su carácter y efectos políticos no lo hacen, sin embargo, refractario al derecho, como en un primer momento se sostuvo ${ }^{70}$. Su adopción requiere

68 J. Porres Azkona, "La decisión sobre poderes excepcionales", Revista Vasca de Administración Pública, núm. 6, 1983, pp. 46-47.

69 J. M. ${ }^{a}$ Rodríguez Oliver, "Los ámbitos exentos del control del Tribunal Constitucional español», en VV.AA.: El Tribunal Constitucional, vol. III, Instituto de Estudios Fiscales, Madrid, 1981, pp. 2319-2320.

70 J. M. Serrano Alberca, "Situaciones excepcionales y fuentes del Derecho en la Constitución española de 1978", en VV.AA., La Constitución española y las fuentes del Derecho, vol. III, cit., p. 1971; F. FERnÁNDEZ SEGADO, "La Ley Orgánica de los estados de alarma, excepción y sitio", cit., p. 113, y J. M. ${ }^{a}$ RODRíGUEZ OLIVER, "Los ámbitos exentos del control del Tribunal Constitucional español», cit., pp. 2317-2320 
la concurrencia de alguna emergencia típica, formalizarse mediante un procedimiento reglado y someterse a ciertos límites. Consecuentemente, la decisión parlamentaria crítica no es un acto político por naturaleza exento de revisión jurisdiccional. Los controles de constitucionalidad y legalidad arbitrados en el Derecho Comparado son buena prueba de ello ${ }^{71}$. Y tampoco es una decisión que carezca de parámetro normativo de contraste suficientemente objetivado, pues el constituyente proporcionó elementos bastantes para su determinación. El problema del control jurisdiccional de la declaración de estado de sitio no radica, por tanto, en sus efectos políticos o en la insuficiencia de la normatividad constitucional, sino en la omisión de la vía procesal adecuada y de título competencial expreso, lo que, sumado a la ambigua naturaleza jurídica de la resolución declaratoria, plantea interrogantes sobre su plena justiciabilidad.

Aunque formalizada mediante resolución parlamentaria, alguna doctrina ha sostenido la naturaleza de ley ad hoc o de disposición normativa con fuerza de ley de la declaración del estado de sitio, pudiendo ser, por ello, objeto de recurso de inconstitucionalidad y, de resultar relevante en el proceso a quo, también de cuestión de inconstitucionali$\mathrm{dad}^{72}$. Pese a su carácter normativo, creemos, sin embargo, que la declaración y la prórroga del estado de sitio no son leyes, ni singulares ni leyes-medida. El concepto exclusivamente formal de ley existente en nuestro ordenamiento lo impide. La ley es "un acto complejo de formación bicameral e imputable, en su adopción, a las Cortes Generales", como ha subrayado el Tribunal Constitucional ${ }^{73}$, lo que no puede decirse de la resolución declaratoria o de la prórroga del estado de sitio, aprobadas únicamente por el Congreso de los Diputados. $Y$ tampoco son disposiciones normativas con rango de ley, categoría reservada en nuestro ordenamiento jurídico para los decretos legislativos y los decretos-leyes.

71 M. E. ÖZBUdun, "Pouvoirs d'exception et contrôle jurisditionnel», en VV.AA., Droits de l'homme et fonctionnement des institution démocratiques dans des situations $d^{\prime}$ urgence, Collection Science et technique de la démocratie, Conseil de I'Europe, Strasbourg, 1997, pp. 18-19.

72 En este sentido, R. MATEU-Ros y Cerezo, para quien la declaración es una leymedida ("Crisis de Estado y fuentes del Derecho", cit., pp. 1400-1401), y P. CRUz VILLALÓN Y A. NAVAS CASTILLO, quienes la definen como disposición normativa con rango de ley (Estados excepcionales y suspensión de garantías, cit., p. 140, y "Los estados excepcionales y su posible control por el Tribunal Constitucionalı, cit., p. 155 , respectivamente).

${ }^{73}$ STC 45/1986, de 17 de abril, fundamento jurídico $3 .^{\circ}$. 
Otros autores han considerado la declaración y la prórroga del estado de sitio como simples actos parlamentarios sin fuerza de ley, resistentes a la jurisdicción ordinaria debido a la autonomía de la Cámara constitucionalmente garantizada, pero impugnables ante el Tribunal Constitucional mediante recurso de amparo ex artículo 42 de la LOTC y, eventualmente, mediante conflicto de atribuciones entre órganos constitucionales o de competencias entre el Estado y las Comunidades Autónomas ${ }^{74}$.

Para la mayoría de la doctrina, sin embargo, ambas decisiones parlamentarias críticas pueden ser caracterizadas como "actos del Estado con fuerza de ley", categoría reconocida en la LOTC como objeto susceptible de control de inconstitucionalidad a fin de reducir un buen número de situaciones de inmunidad jurisdiccional ${ }^{75}$. Dada la indeterminación de la expresión "actos con fuerza de ley", algunos autores han considerado dotados de esta fuerza tan sólo a los actos jurídico-públicos de incidencia normativa en los que el Parlamento o una de sus Cámaras interviene en su procedimiento de adopción. La "fuerza de ley" sería así una cualidad derivada de la intervención parlamentaria ${ }^{76}$. Para otros, en cambio, dicha fuerza tendría que ver con la condición de complemento imprescindible para la plena efectividad de ciertos preceptos constitucionales o para la validez de normas jurídicas con rango de ley que caracteriza a algunos actos o decisiones del Estado, independientemente de su procedencia parlamentaria y del carácter simple o complejo del procedimiento establecido para su adopción. Los actos con fuerza de ley serían, de este modo, todos aquellos directamente incardinados en la Constitución, no sometidos, por ello, a control de legalidad sino de constitu-

74 M. a J. Alonso MAS, La fiscalización jurisdiccional de la actividad sin valor de ley de los Parlamentos, Centro de Estudios Políticos y Constitucionales, Madrid, 1999, pp. 148-150

75 R. PUnSET Blanco, "El control jurisdiccional de la actividad de las Asambleas parlamentarias y del estatuto de sus miembros en el Derecho español», en Estudios parlamentarios, Centro de Estudios Políticos y Constitucionales, Madrid, 2001, pp. 381-382, y M. Aragón Reyes, "Artículo 161. Competencias del Tribunal Constitucional», en O. Alzaga VillaAmil (dir.), Comentarios a la Constitución española de 1978, tomo XII, Edersa-Cortes Generales, Madrid, 1999, p. 200.

76 En este sentido, M. Aragón ReYes, "Acto con fuerza de ley», en M. Aragón ReYES (coord.), Temas básicos de Derecho Constitucional, tomo I, Civitas, Madrid, 2001, p. 342, y A. NAVAS CASTILLO, El control jurisdiccional de los actos parlamentarios sin valor de ley, Colex, Madrid, 2000, pp. 46-50, quien con el tiempo matizó su opinión inicial sobre las decisiones de crisis. 
cionalidad ex artículo 27.2.b) de la LOTC ${ }^{77}$. Esta última es la tesis que suscribo por varias razones.

En los ordenamientos constitucionales modernos, la mayoría de las decisiones jurídico-públicas políticamente vitales siguen precisando forma de ley, pero junto a éstas existen otras decisiones igualmente relevantes que, por no contener propiamente normas, son adoptadas por las Cámaras bajo la forma de acuerdos o resoluciones, o incluso por el Gobierno. Y no por ello pierden la fuerza de las decisiones legislativas. Al contrario, son actos con fuerza de ley, lo que no quiere decir que puedan derogar leyes formales - cosa que no pueden hacer hoy muchas leyes respecto de otras determinadas-, sino que tienen el mismo valor y el mismo rango que las leyes. No en vano, aplican directamente un precepto constitucional o constituyen complemento necesario para su aplicación, "realizando", de este modo, la Constitución. Son, por ello, actos primarios, como aquellas son normas primarias. Pero a diferencia de las leyes, que pueden tener cualquier contenido, estos actos siempre versan sobre materia constitucional. No son propiamente normas, porque no contienen mandatos generales y abstractos que se incorporen establemente al ordenamiento jurídico. Tampoco son actos administrativos, porque ni su contenido ni la competencia de su titular están legalmente reglados, sino constitucionalmente reglados. $Y$ ello, sin perjuicio de que en ocasiones la normatividad constitucional haya debido ser completada por una norma legal a la que aquella se remitía y que, por esa razón, se convierte también en canon o parámetro de referencia para el correspondiente juicio de constitucionalidad.

La declaración del estado de sitio y su eventual prórroga pertenecen, en nuestra opinión, a esta categoría de actos. No son formalmente normas, ni modifican el ordenamiento jurídico. Son decisiones singulares y concretas directamente subordinadas a la Constitución que dejan en suspenso el estatuto ordinario del poder y de las libertades, sustituyéndolo por otro alternativo de emergencia. Resultan absolutamente imprescindibles para la "realización» del derecho constitucional de excepción, cuya efectividad está condicionada a la declaración de la

77 J. PORRES AZKONA, "La decisión sobre poderes excepcionales», cit., p. 47; A. M. García CuAdrado, "Los actos parlamentarios con fuerza de ley", Corts. Anuario de Derecho Parlamentario, núm. 7, 1999, pp. 283-286, y, especialmente, "Aproximación a una teoría de los "actos constitucionales"», Revista de Derecho Político, núm. 46, 1999, pp. 44-49, así como C. Aguado Renedo, Problemas constitucionales del ejercicio del derecho de gracia, Civitas, Madrid, 2001, p. 247. 
crisis. Presuponen, por ello, interpretación y aplicación de la normatividad constitucional, completada por la LOAES debido a la reserva expresa del propio constituyente. Las decisiones parlamentarias de crisis determinan el régimen jurídico de la situación crítica, operando como fuente de habilitación de disposiciones y actos ejecutivos. Su dimensión normativa es evidente, pues contienen mandatos que se proyectan sobre un número indeterminado de situaciones. Dichos mandatos no se incorporan al ordenamiento ni lo modifican, por lo que no son normas stricto sensu, aunque "ocupan el lugar de una verdadera norma a la hora de enjuiciar la validez de los actos administrativos que se dicten apoyándose en la declaración ${ }^{78}$. Son, en fin, decisiones de naturaleza compleja — formalmente actos, materialmente normas-con incidencia constitucional.

Consecuentemente, las decisiones parlamentarias de crisis no son leyes, ni disposiciones normativas con rango de ley. $Y$ tampoco son actos parlamentarios sin valor de ley. Pese a formalizarse mediante resolución parlamentaria, su naturaleza jurídica y dimensión normativa permite caracterizarlas como "actos del Estado con fuerza de ley" ex artículo 27.2.b) de la LOTC, y, consiguientemente, residenciar su control ante el Tribunal Constitucional. En cuanto directamente inconstitucionales, dichos actos son susceptibles de declaración de inconstitucionalidad mediante recurso directo y, al habilitar la adopción de disposiciones reglamentarias y actos de aplicación, también, eventualmente, mediante cuestión de inconstitucionalidad.

Cuestión distinta es, por supuesto, la eficacia que la garantía jurisdiccional de la Constitución puede llegar a alcanzar en situaciones de grave anormalidad, sobre la que no cabe albergar demasiadas esperanzas. La violación de la Constitución por el poder de excepción no tiene una sanción jurídica fácil, pues éste siempre podrá alegar en su descargo el socorrido principio de necesidad o la "razón de Estado". Pero una cosa es ser consciente de las limitaciones de la justicia constitucional en tiempos de crisis y otra bien distinta negarle de antemano cualquier virtualidad para evitar los abusos. El Estado de Derecho no admite inmunidades del poder, por lo que el control jurisdiccional de estas decisiones ha de estar garantizado. Su existencia es la mejor garantía frente a quien decide sobre el poder de excepción, que de otro modo podría devenir en soberano, como Schmitt advirtión ${ }^{79}$. El control

78 A. M. García CuAdrado, "Aproximación a una teoría de los "actos constitucionales"'", cit., p. 52.

79 C. SchmitT, Teología política. Cuatro ensayos sobre la soberanía, Editorial Struhart \& Cia., Buenos Aires, 1998, p.15. 
de constitucionalidad le protege, ante todo, de sí mismo, neutralizando sus tentaciones. Y allí donde el control está verdaderamente instituido, la amenaza de la deslegitimación constitucional pesa. Acaso sea esta amenaza el mayor y más eficaz freno del titular de la decisión de excepción.

\section{Resumen}

La excepción requiere la adopción de medidas excepcionales. Y cuando ésta pone en peligro, con amenazas o agresiones armadas, elementos básicos del Estado, como la soberanía, la integridad territorial o el ordenamiento constitucional, la respuesta excepcional del Estado ha de ser la más extrema e implicar el uso de la fuerza militar. En el Estado de Derecho, sin embargo, la reacción extraordinaria ante lo fáctico no puede ser incondicionada, ni invalidar sus fundamentos. De ahí que el estado de sitio previsto en el artículo 116 de la CE sea, pese a la gravedad que entraña su utilización, una garantía de la Constitución, no su desahucio. El estado de sitio habilita la concentración de poder y la gestión militar de la crisis; la supremacía del Derecho y del poder civil queda, con todo, garantizada. Al estudio de la naturaleza de esta institución excepcional, de su régimen jurídico y de su control jurisdiccional se dedica este trabajo, que parte de la constatación de las hondas diferencias que separan su actual función constitucional de la de sus precedentes. A efectos sistemáticos, el autor aborda en primer término la gestación normativa del instituto y los presupuestos que habilitan su declaración; $y$, seguidamente, distingue entre el estado de sitio, la declaración de guerra y los tiempos de guerra, expresiones utilizadas por el constituyente para aludir a situaciones distintas aunque eventualmente conexas. Por lo que respecta a su régimen jurídico, se analizan la función del bando militar bajo el principio de legalidad penal, el ámbito de la jurisdicción castrense, los posibles efectos sobre el régimen jurídico de las libertades, los supuestos de gestión militar de la emergencia y las resistencias que la Constitución impone al poder de excepción. Al término del trabajo se estudian los procedimientos de declaración, prórroga y cese de este estado crítico, así como las dificultades existentes para caracterizar jurídicamente las decisiones de declaración y prórroga como "actos del Estado con fuerza de ley" y, consecuentemente con ello, atribuir su control jurisdiccional al Tribunal Constitucional.

\section{Palabras clave}

Estados excepcionales, Fuerzas Armadas, control. 


\title{
Title
}

«MARTIAL LAW, ITS LEGAL FRAMEWORK AND JURISDICTIONAL MONITORING OF THE DECLARATION THEREOF»

\section{Key words}

States of exception, Armed Forces, monitoring.

\section{Summary}

1. Legal nature of martial law and motives for the declaration thereof.- 2. Martial law, declaration of war and "time" or "times" of war.- 3. Military decrees and the principal of penal legitimacy. Scope of military jurisdiction in martial law.- 4. Effects on the legal framework of liberties and the ordinary statute of power.- 5 . Constitutional checks on the power of exception.- 6. Declaration, extension and termination procedures.- 7. Legal nature and jurisdictional monitoring of parliamentary decisions on the declaration and extension of martial law.

\begin{abstract}
Exception calls for the adoption of unique and extreme measures. Under the Rule of Law, however, no limit may be placed on the extreme reaction to it, nor can its basic tenets be invalidated. Hence martial law, as envisaged in article 116 of the Spanish Constitution is, in spite of the serious significance its use implies, a guarantee of the Constitution; it does not constitute its abolition. Martial law provides concentration of power and military handling of crisis; and yet the supremacy of Law and civil power is safeguarded. The study of the nature of this institution of exception, its legal framework and jurisdictional monitoring makes up one part of this paper, which starts off by noting the major differences distinguishing its current constitutional function to that of its antecedents. Systematically, the author examines, firstly, the gestation of the regulations governing the institution and the motives for the declaration thereof; next, the distinction is made between martial law, the declaration of war and times of war, expressions used to refer to situations that are distinct although incidentally connected. With regard to the legal framework of this state, analysis is made of the function of the military decree under the principal of penal legitimacy, the scope of military jurisdiction, potential effects on the legal framework of liberties, the motives for military handling of the emergency and Constitutional checks on the power of
\end{abstract}


exception. The paper concludes with a study of the procedures for the declaration, extension and termination of this state of exception, as well as the problems involved in identifying the legal characteristisation of declaration and extension decisions as "acts of the State with the force of law», thereby ascribing jurisdictional monitoring of the situation to the Constitutional Tribunal. 